\title{
Stakeholder engagement and involvement in nuclear emergency preparedness - the Slovak Republic's experience in RODOS tool-driven workshops
}

\author{
J. Bohunova ${ }^{1}$, T. Duranova ${ }^{1}$, P. Jurka ${ }^{2}$ and M. Makovnik ${ }^{2}$ \\ 1 VUJE, Inc., Okruzna 5, 91864 Trnava, Slovak Republic. \\ 2 Nuclear Regulatory Authority of the Slovak Republic, Bajkalská 27, 82007 Bratislava, Slovak Republic.
}

\begin{abstract}
The facilitated workshops driven by exercise scenarios using decision support tools customised to national conditions have proven to be efficient, with a focus on possible real problems and finding real solutions. The stakeholders of the Slovak Republic actively entered the post-accident preparedness process with the objective "to increase the coherence and effectiveness of nuclear and radiological emergency management in Europe, including the rehabilitation of contaminated areas through the establishment of an effective working platform of emergency management institutions, research institutes, end-users and other stakeholders for initiating application-oriented improvements of methods, procedures, guidelines and information tools". After the experience within the EVATECH Project, there was a clear statement from all stakeholders that facilitated workshops and work in such multidisciplinary and multilateral groups are challenging, yet rewarding for them. As was seen later on in the process, this type of work was very successful, efficient, and made an essential basis for future activities in post-accident preparedness process development and for building networks and trust between partners within the Slovak Republic and within Europe in the EC projects.
\end{abstract}

Keywords: Stakeholder involvement / emergency preparedness / workshops / decision support tools / Slovakia

\section{Introduction}

The Slovak Republic's experience in RODOS tool-driven workshops started with the EVATECH project (EVATECH, 2005). The main targets within this project included:

- development of a method for stakeholder involvement in exercises and emergency planning,

- development of methodologies to conduct scenariofocused decision-making workshops,

- training in using available computer-aided techniques (RODOS, Web-HIPRE) in decision analysis, and

- conducting facilitated decision-making panels or workshops.

In order to achieve these targets, the first facilitated workshop was prepared and conducted in 2003.

Many participants appreciated the future possibility of using the RODOS system with the Web-HIPRE software as an integrated or directly connected tool. They also expressed the need for similar workshops for training purposes with invitation of other specialists from different areas and a focus not only on advisers, but also on leaders who are members of the emergency commissions at different levels, and on residents, who are expected to execute some of the countermeasures. All participants agreed that the countermeasures in inhabited areas have to be discussed again in more detail and thoroughly during a dedicated workshop.

Stakeholders agreed on evolving a decision-framing process within and between stakeholders that is inclusive and participatory, with open and two-way discussions, leading to relationships where issues can be identified, discussed and resolved, resulting in sustainable decisions (Duranova, 2016). This was the main motivation and goal of the common activities.

\section{Experiences}

The need for training and exercising of the recovery and rehabilitation issues at national, regional and local levels, which was expressed within the stakeholder panel during the EVAT$\mathrm{ECH}$ project, led to the organisation of training courses in the form of lectures, workshop sessions and facilitated discussions to demonstrate, use and establish strategies for the use of decision support tools (mainly RODOS) in the decision-making process. The active participation of a wide range of stakeholders in these activities resulted in better structured decision processes at national, regional and local levels involving the 


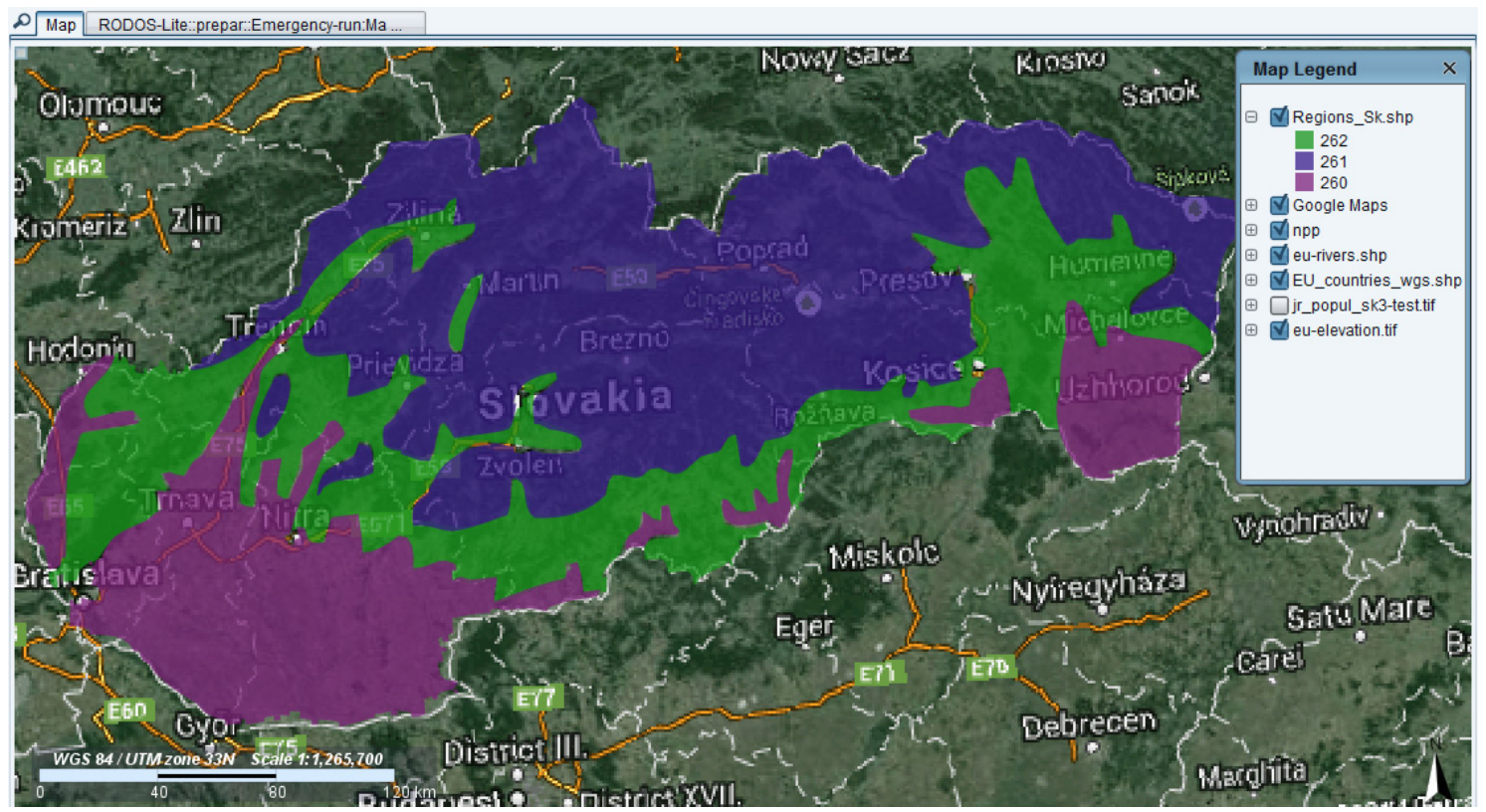

Figure 1. Example of customisation: subdivision of the Slovak Republic territory into 3 regions that differ in growing cycles and agricultural practices implemented in the system JRODOS.

different categories of stakeholders (public authorities, professionals and inhabitants), more accurate information for the emergency and recovery stakeholders, and more efficient use of existing decision support systems and tools. The content of the training courses covered the major issues that require decision-making for mitigation of consequences in case of severe nuclear accidents, including:

- assessment of habitability of areas affected by a nuclear accident

- controlling radiation doses to workers and the public, and

- crisis intervention, intervention criteria and application of intervention levels and countermeasures.

Based on these ideas and aims, two training courses were developed and conducted by VUJE within the EURANOS project (Raskob et al., 2010). The latest versions of RODOS or JRODOS were used during training courses, including the results of LSMC, EMERSIM, ERMIN and the Multi-Criteria Decision Analysis (MCDA) tool Web-HIPRE for decision analyses and thorough discussion of strategies developed by using, at that time, the EURANOS Handbooks for managing contaminated food production systems, drinking water and inhabited areas in Europe (Nisbet et al., 2010).

The stakeholder panel was set up and convened in Slovakia to determine the suitability of such a handbook with regard to its scope, format and content, and further, its customisation needs to the Slovak Republic conditions. In a second round of stakeholder panels they were reconvened to provide feedback on the overall applicability of the handbook, including the annexes, for customising it for different regions of the EU. The findings were taken into account during finalisation of the first versions of the handbook.

The local-national forum for improvement of both local and national capabilities in planning, preparedness, response and recovery for nuclear and radiological emergency continued its work within the NERIS-TP project by:

- introducing the existing tools to stakeholders, such as RODOS, Handbooks and WebHIPRE (for new users and refreshers),

- adaptation of existing tools to their needs, based on feedback, and

- testing of adapted tools.

In 2011, a facilitated workshop was developed which focused on the practical use of the Handbook for Assisting in the Management of Contaminated Inhabited Areas (translated and adapted to the Slovak conditions and legislation) following an accident at Mochovce nuclear power plant. The selection of countermeasures and strategy development was based on a scenario developed using the RODOS Linux system, adapted to the Slovak Republic conditions.

The customisation and adaptation of new versions of JRODOS to assist the municipalities in preparing for the localregional cooperation took place. JRODOS was customised to the Slovak Republic conditions related to the users, source term databases for Bohunice and Mochovce NPPs, configuration and management of JRODOS databases (GeoDB and GisDB), data and parameters for JRODOS models, numerical weather prediction data for LSMC and MATCH, AOI and other factors for ERMIN, radioecological region data, and others (Figures 1 and 2).

At the end of 2013 a facilitated workshop was organised with the following main objectives:

- to demonstrate and use the new products of the decision support system JRODOS at all levels of the crisis management,

- to give feedback to developers on the users' experience, 


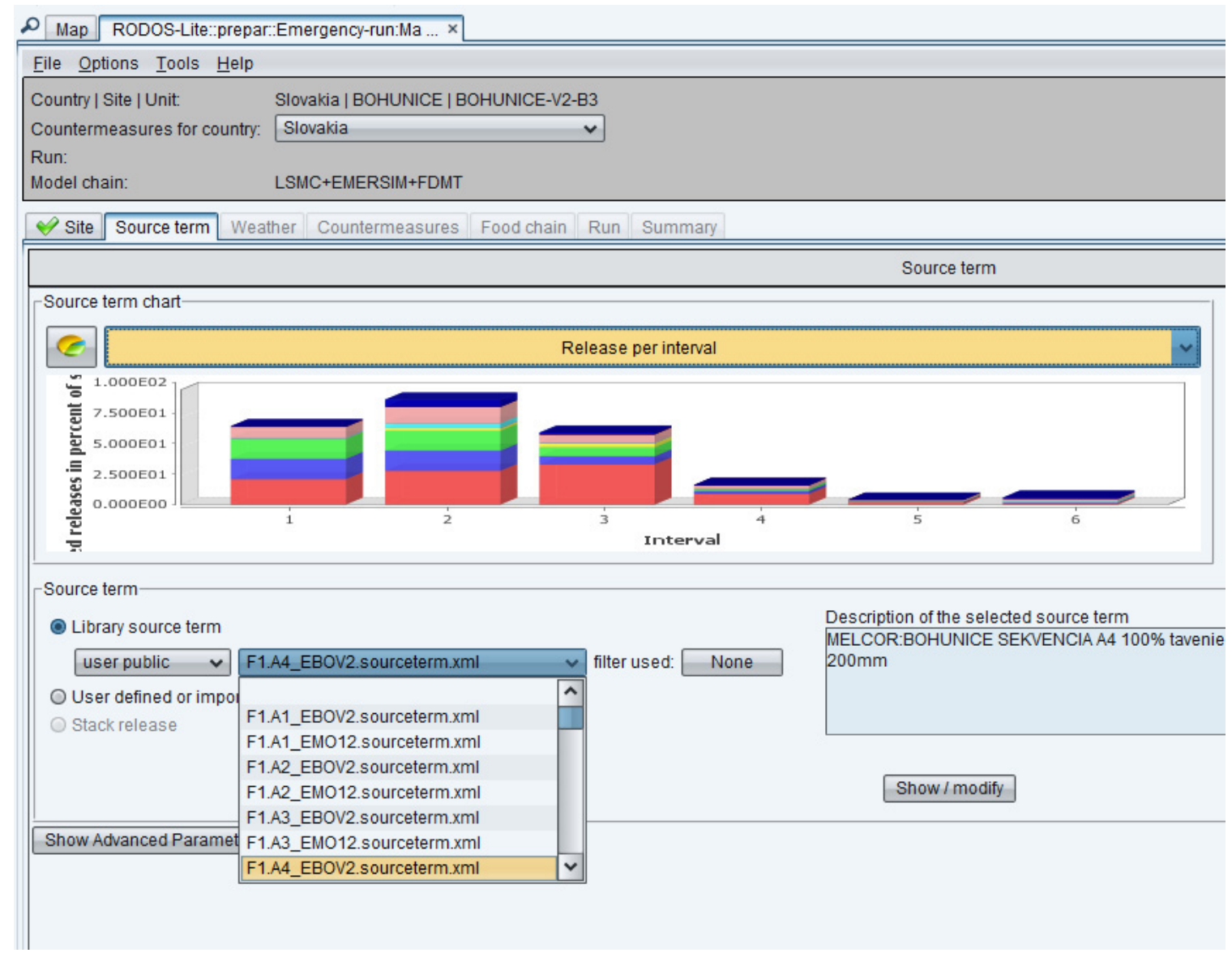

Figure 2. The database of 34 pre-calculated source terms for power operation modes for each Slovak nuclear power plant defined as a fraction of inventories implemented in the DSS JRODOS.

- to evaluate the process of stakeholder involvement and particular stakeholder workshops/seminars/training since 2003 in Slovakia, and

- discuss the enhancement and sustainability of the process.

During the workshop, the newest JRODOS version was interactively used, including the new ICRP screening tool (Landman et al., 2015), and ERMIN2 (Charnok et al., 2010, 2016) and AgriCP (Gering et al., 2010) modules with an accident scenario applied to the Mochovce NPP site, that attracted stakeholders to participate actively and discuss the urban and agricultural area aspects (Figure 3).

\section{Conclusions}

The stakeholders were very grateful for the opportunity to explore recovery issues in the framework of the seminars and workshops conducted, and they felt that the Web-HIPRE decision software was a useful input to the process. The process contributed significantly to changing the patterns of relations between the stakeholders involved, but continuous and systematic development and cooperation is needed in the future, especially between national and local dimensions. The cooperation is better between regional and local dimensions, as confirmed by exercises performed with a focus on the emergency preparedness and response.

Working in the form of facilitated workshops with scenarios developed using customised operational decision support tools (RODOS, RTARC), Handbooks translated and adapted to the Slovak conditions and legislation, and the MCDA tool Web-HIPRE made the work more efficient, with a focus on possible real problems and finding real solutions. In particular, the new ICRP Screening tool, and ERMIN2 and AgriCP modules, which are closely connected to the Handbooks, were proven to be very useful. Communication between different stakeholders involved in the active work at facilitated workshops, seminars, workshops, training courses and exercises was found to be very important to have a balanced view on various aspects of the issues at the national, regional or local levels. The workshops showed that this form is efficient, acceptable and suitable for all stakeholders at all levels (national, regional and local) and could be applied within a national policy in the area of emergency preparedness and response.

The framing of the emergency and post-accident issues changed during the course of the process, especially the postaccident issue. More transparently, it was confirmed by the preparation and conducting of the INEX 4 Exercise when different groups of stakeholders were formed, who were well prepared to communicate and coordinate their activities, but who 


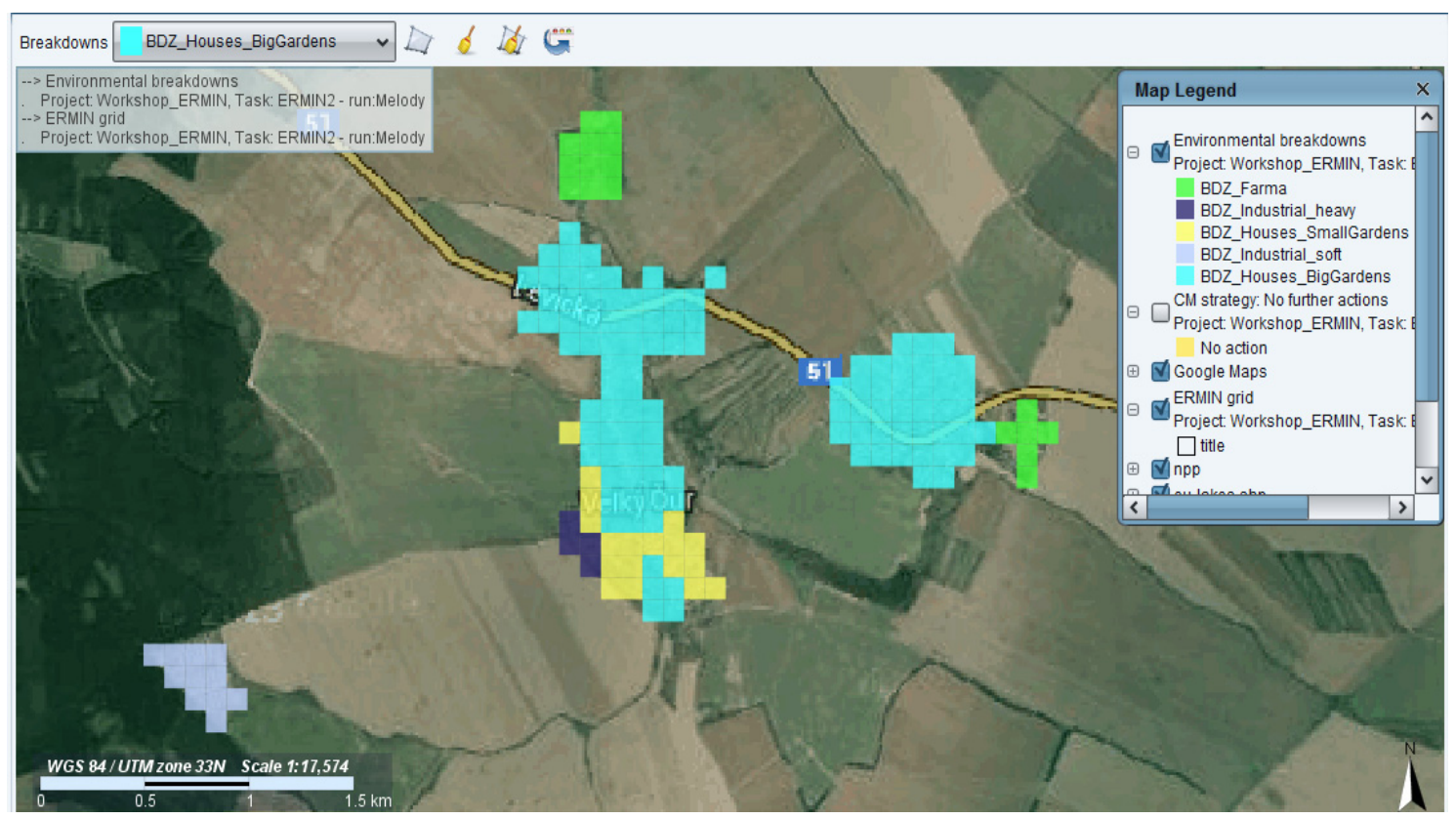

Figure 3. ERMIN2 - environmental breakdown: the definition of the environmental composition of the area of interest - the village Velky Dur, situated about 5-6 km south-east of the Mochovce NPP.

also recognised gaps and issues for improvement in the area of emergency preparedness and post-accident management. The understanding of the importance of preparedness for the post-accident issues and the complexity of the processes and their time frame embedded the radiation protection goal into a larger perspective involving several aspects of life quality that would be potentially affected. The exercise outputs encouraged deeper analysis of the situation in the Slovak Republic in the area of emergency planning and preparedness, and the later Fukushima disaster and response to the situation accelerated the process of design and development of the "Concept of the organisation and development of Civil Protection" and "Concept of organisation, operation and development of the Integrated Rescue System” in the Slovak Republic.

\section{References}

Charnok T.W. et al. (2010) The European model for inhabited areas (ERMIN) - developing a description of the urban environment. In: Enhancing Nuclear and Radiological Emergency Management and Rehabilitation, Key Results of the EURANOS European Project (W. Raskob, M. Hugon, Eds.), Radioprotection 45 (5), S55-S61.

Charnock T., Landman C., Trybushnyi D., Ievdin I. (2016) European Model for Inhabited Areas - ERMIN 2, Radioprotection 51 (HS 1), S23-S25.

Duranova T. (2016) The Slovak experience with local-national fora - overview of the framework and process description, Radioprotection, 51 (HS1), S35-S37.
EVATECH (2005) Information Requirements and Countermeasure Evaluation Techniques in Nuclear Emergency Management, Final Technical Report, 30 June 2005.

Gering F., Raskob W., Charnok T.W. (2010) New model for agricultural countermeasures in RODOS and ARGOS. In: Enhancing Nuclear and Radiological Emergency Management and Rehabilitation, Key Results of the EURANOS European Project (W. Raskob, M. Hugon, Eds.), Radioprotection 45 (5), S63-S76.

Landman C., Raskob W., Trybushnyi D., Ievdin I. (2015) An application example for the new ICRP screening tool of JRodos, Radioprotection, 51 (HS1), S17-S22.

Nisbet A.F., Brown J., Howard B.J., Beresford N.A., Ollagnon H., Turcanu C., Camps J., Andersson K., Rantavaara A., Ikäheimonen T., Duranova T., Oughton D., Kirchner G., Papachristodoulou C., Ioannides K., Kwakman P. (2010) Decision aiding handbooks for managing contaminated food production systems, drinking water and inhabited areas in Europe. Enhancing Nuclear and Radiological Emergency Management and Rehabilitation, Key Results of the EURANOS European Project (W. Raskob, M. Hugon, Eds.), Radioprotection 45 (5), S23-S37.

Raskob W., Gering F., Lochard J., Nisbet A., Starostova V., Tomic B. (2010) Overview and main achievements of the EURANOS project: European approach to nuclear and radiological emergency management and rehabilitation strategies. In: Enhancing Nuclear and Radiological Emergency Management and Rehabilitation, Key Results of the EURANOS European Project (W. Raskob, M. Hugon, Eds.), Radioprotection 45 (5), S9-S22. 